\title{
Discrimination learning in the sooty agouti (Dasyprocta fuliginosa)
}

\author{
ROBERT C. ERFFMEYER and ROBERT S. HARPER \\ Knox College, Galesburg, Mlinois 61401
}

\begin{abstract}
Using a modified WGTA, a male and a female agouti were exposed to five discrimination problems: three simple A-B discriminations (two white-black, one circle-square) and two A-B-B discriminations. The problems were readily solved, with the shift from the incorrect to the correct response being made rather abruptly, reminiscent of the hypothesis-testing behavior of Kreschevsky's (1932) rats.
\end{abstract}

The agouti is a large rabbit-sized rodent found from northern South America to southern Mexico. Although a reasonably common zoo animal, only one article describing its behavior has been located (Roth-Kolar, 1957). This article includes a brief comment on its learning ability. After 14 days of using a bamboo pole to chase his agoutis from their bed, Roth-Kolar, while standing on the far side of the room, had only to grasp the stick in his hand to make them leave their bed. But, he said, "this negative training, which moreover was never quite reliable, they soon forgot again." His agoutis also buried their food, with no effort to conceal their actions from other animals, and appeared to forget quickly where they had buried it. On the basis of these observations, Roth-Kolar concluded: "Learning ability and spatial orientation are rather inconsiderable in the agouti." The present study is simply an exploratory study, under more controlled conditions, of discrimination learning in the agouti.

\section{METHOD}

One male and one female sooty agouti, approximately 3 years old, originally from the Brookfield, Illinois, Zoo, were obtained on loan from the Niabi Zoo, Rock Island, Illinois. At the zoos, the animals had been housed together in display pens and had not been used in any behavioral studies. At Knox College, the animals were housed in an $8 \times 10 \times 7 \mathrm{ft}$ controlledenvironment chamber at a temperature of $29^{\circ} \mathrm{C}$ with ad-lib water. A light/dark schedule of $11 / 13 \mathrm{~h}$, respectively, was maintained. Inside the chamber, in the corners on each side of the central door, a $2 \times 2 \mathrm{ft}$ litter box was placed on the metal floor, leaving a $2 \times 4 \mathrm{ft}$ space between the boxes for the experimenter's work space. The remaining floor space was covered with plywood to facilitate the agoutis' walking. The experimenter's space was screened from the animal's living space by a 3-ft-high partition of chicken wire. The agoutis were fed in the afternoon, with the experimental sessions immediately preceding their feeding on test days.

For testing, a plywood cover was placed over one litter box and a solid wood partition was placed between the litter box and the rest of the living chamber, thus creating a $2 \times 2 \times 2 \mathrm{ft}$

The first author is now at Louisiana State University. Our special thanks to Larry Weston, Director, and Julie Johnson, both of Niabi Zoo, for their assistance and cooperation in obtaining the agoutis. cubicle with solid walls on three sides and chicken wire on the fourth. Through a flap in the chicken wire, an apparatus similar in principle to a Wisconsin General Test Apparatus could be inserted. This was a prism-shaped device, with a wooden base $18 \mathrm{in}$. wide and $10 \mathrm{in}$. deep, and a height of $12 \mathrm{in.}$ on the open side toward the experimenter. The ends were solid. A sliding Masonite panel on the sloping side toward the animals could be raised at the beginning of each trial to give them access to the discrimination problem. The base contained two (later three) wells, $1 / 4$ in. deep and 2 in. in diam. The reinforcer, a raisin, was placed in one well, then covered with the positive stimulus object, and the other well (or wells) was covered with the appropriate negative stimulus objects. The stimulus objects were 3 -in. disks or $2 \frac{1}{2}$-in. squares, cut from $3 / 4$-in. wood and painted either black or white.

Each animal, on each test day, was given 25 trials, with the opportunity to continue responding (i.e., moving the stimulus object off the well with its snout) until obtaining the reinforcement. In 4 days of preliminary training, during which both wells contained raisins and both wells were covered with white squares, the animals learned to enter the test area with no urging. As soon as the cover was placed on the litter box, the male would enter and wait for the solid partition to slide into place. At the end of his trials, as the partition was moved aside, the male would leave and the female, who had been quietly sitting on the other side, would enter.

Following preliminary training with the two white squares, the experimental regimen began: Task 1, 6 days, white square positive, black square negative; Task 2, 21 days, black square positive, white square negative (the reversal problem for Task 1); Task 3, 16 days, black square positive, black disk negative; Task 4, 3 days, black square positive, two black disks negative (an A-B-B problem intended as an introduction to an eventual oddity problem); Task 5, 17 days, black disk positive, two black squares negative (the reversal problem for Task 4). The left, right, or center position of the positive stimulus was randomly varied, using a table of random numbers, on each trial (with the restriction that one position could be positive no more than 13 times per 25 trials on Tasks 1,2 , and 3, or approximately one-third of the daily trials on Tasks 4 and 5).

\section{RESULTS}

The results for Tasks 1 through 4, expressed in terms of the probability that the animal's first response would be a correct response, are shown in Figure 1. The results for Task 5, expressed in terms of the probability of either one of two particular first-response possibilities being correct, are shown in Figure 2. 


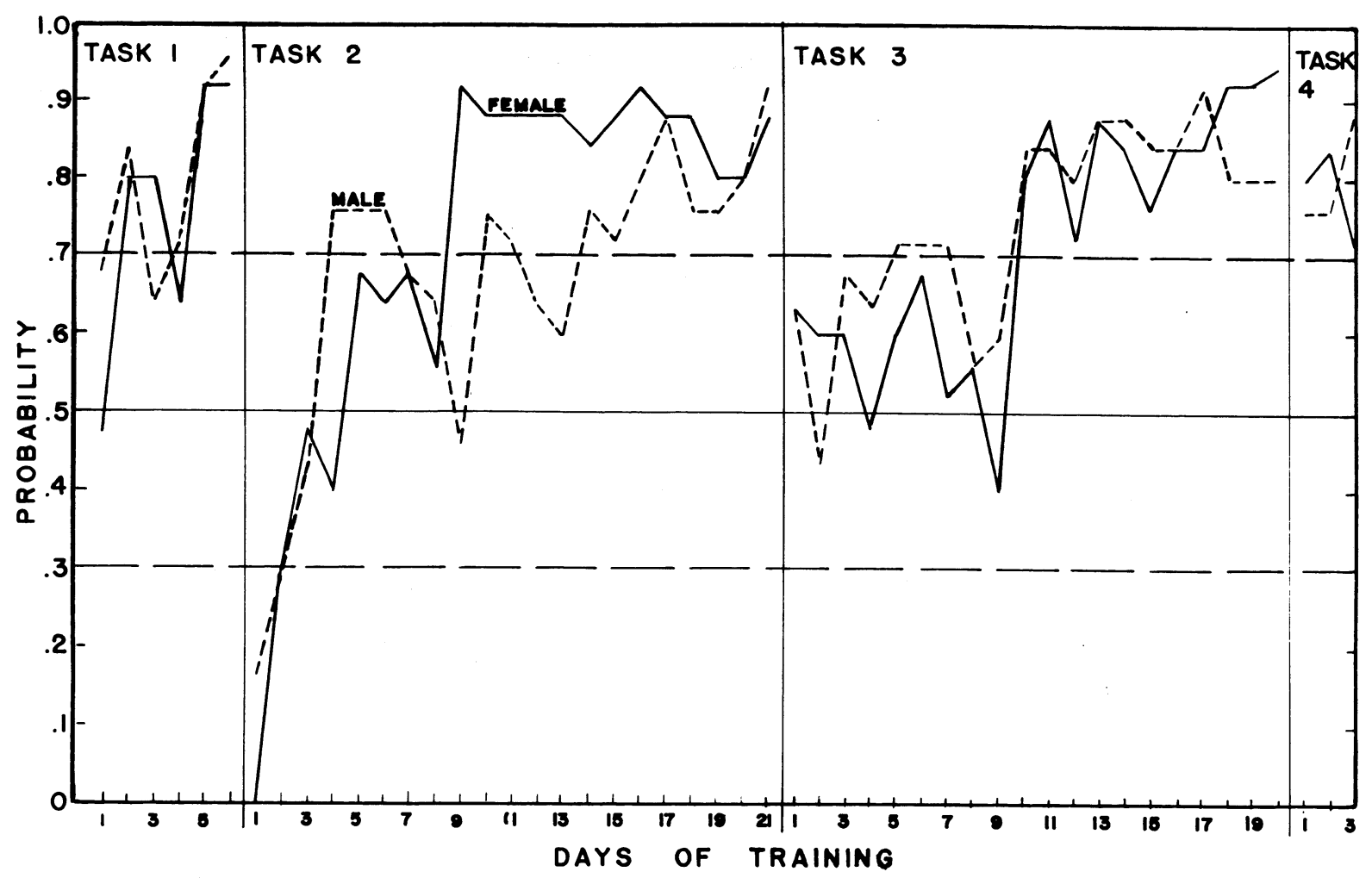

Figure 1. The probability of the first response being a correct response during acquisition of three two-choice and one three-choice discriminations by a male (dotted line) and a female (solid line) agouti. The four tasks were, respectively: white square positive, black square negative; black square positive, white square negative; black square positive, black disk negative; black square positive, two black disks negative.

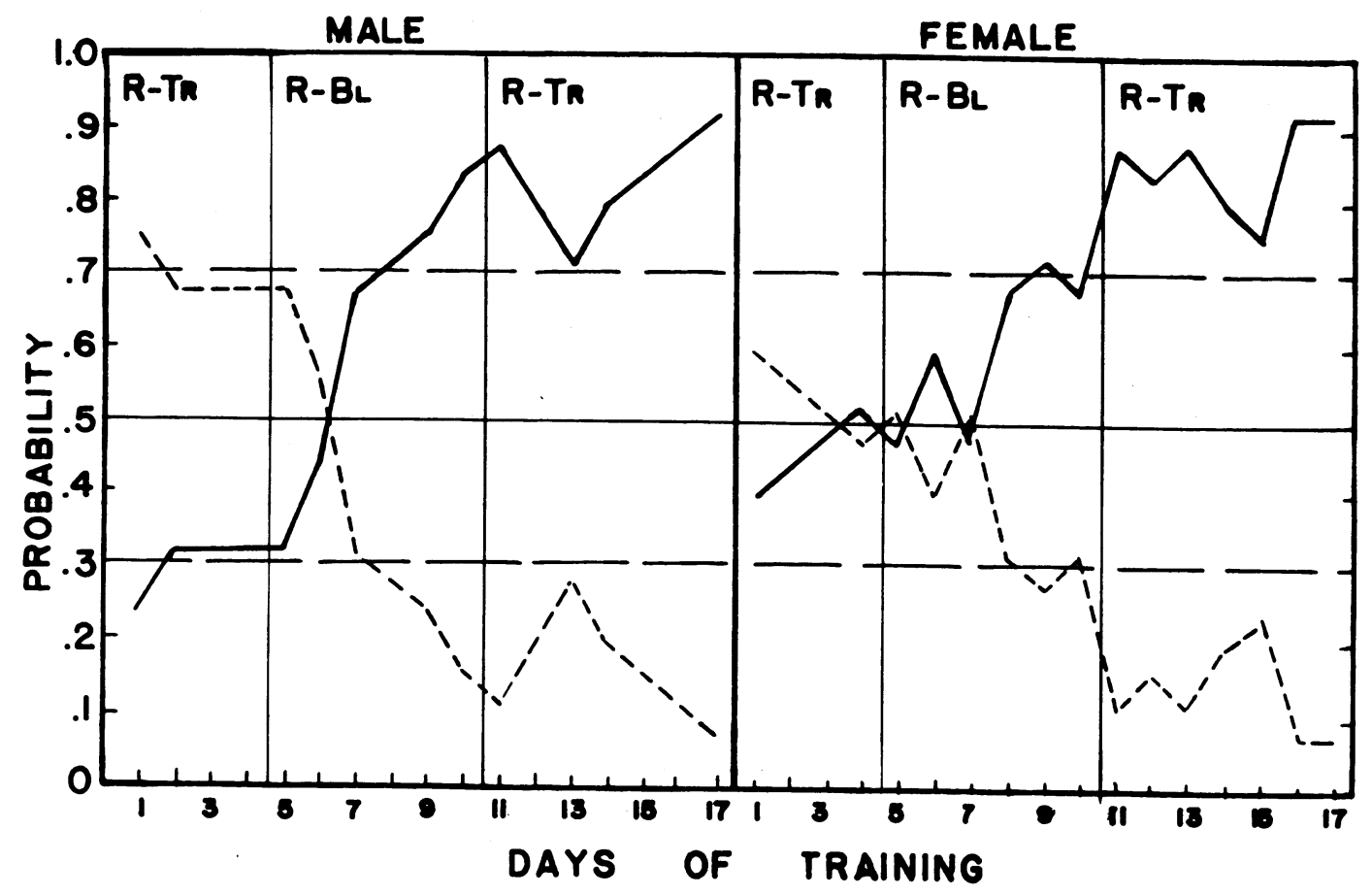

Figure 2. The probability of the first response being to one of two square objects (dashed line) or to the single disk (solid line) during acquisition of the single-disk response by a male and a female agouti. The square always had been correct during the preceding 23 days. $R$-Tr indicates random change of the position of the single disk on each of the daily 25 trials. R-B1 indicates such change only between each of the five daily blocks of five trials each. 


\section{DISCUSSION}

Task 1 , which only added a negative stimulus to the preliminary training task, was no problem for either animal. The reversal task posed by Task 2 , however, was difficult. Both agoutis persevered in the old response, a tendency that was supported by the extreme rapidity with which they made their response. However, reminiscent of the hypothesis-testing behavior of Kreschevsky's rats (1932), both animals showed an abrupt change in behavior on Days 9 and 10 . On Task 3, a similar abrupt shift occurred on Day 10. Task 4, like Task 1, was essentially no problem, since it merely added a second negative stimulus object. Task 5 , however, was a problem. The subjects could respond to the previously positive black square, or they could respond to the positive odd disk, or to a particular position, or to some pattern of shapes and locations. The animals' behavior pattern during the first 4 days showed so little change that we thought we might be overloading them with too many changes too frequently, thus our decision to change the location of the positive shape only every fifth trial for Day 5 through Day 10. As is evident, 2 days of the simpler regimen (or 6 days altogether) were sufficient for the agoutis to acquire "respond to the single disk" behavior, a response pattern that persisted when random changes on each trial were reinstituted on Day 11. The slight trend for the new response to appear sooner on successive tasks suggests that the animals might have been "learning to learn." The necessity of returning the agoutis to the zoo at the end of the term prevented implementation of a full-fledged oddity problem.

Our agoutis were friendly animals, quickly adapting to their new environment, readily eating from the hand, usually using their litter box, and giving off no significant odor. Contrary to Roth-Kolar's (1957) disparaging conclusion, the behavior we observed in our agoutis seemed to be that of an intelligent organism, interacting with its environment in a systematic way, and adapting to new situations at a rate commensurate with other rodents.

\section{REFERENCES}

Krechevsky, I. "Hypotheses" in rats. Psychological Review, 1932, 39, 516-532.

Roth-Kolar, H. Beitrage zu einem Aktionssystem des Aguti (Dasyprocta aguti aguti L.). Zeitschrift für Tierpsychologie, 1957, 14, 362-375.

(Received for publication October 13, 1976.) 